\title{
An Integrated Approach to Management of Short Stature In Children: Review Article
}

\author{
Bajracharya L \\ Assistant professor, Department of Paediatric, Tribhuvan University Teaching Hospital, Kathmandu, \\ Nepal.
}

\begin{abstract}
Short stature in children is a very common condition that requires timely investigations and management. Although there has been dramatic reduction in stunted growth in children below the age of 5 years during the last two decades in Nepal, the process of systemic screening and evaluation followed by timely treatment can still be made better. Awareness programs for short stature such as at the time of birth of baby and use of social media for its dissemination in public can enhance short stature screening programs in schools, local ward clinics and other child health welfare programs as immunization. Children with suspected short stature can then further be referred to higher health centers as per need for investigations and management. Data generated may then be later used to develop algorithms and plan strategies to incorporate height well being in child healthcare policies. An integrated approach is necessary for maximum benefit.
\end{abstract}

Key Words: Integrated Approach, Short stature, Children

\section{Introduction}

Short stature is very common reason for a child to be referred to a doctor. ${ }^{1}$

How much psychosocial stress it can cause to a child depends on the severity of the height deficit, the degree of tolerance in the local population, and the child's coping skills. ${ }^{2}$

Short stature is defined as a height more than two standard deviations below the mean for age or less than the 3 rd percentile. It is called idiopathic short stature when the cause in not known. ${ }^{3}$ Growth pattern of a child has been considered as a marker for overall general health of a child and having short stature may signify a serious illness as well. ${ }^{4,5}$ Although boys may face more social pressure as compared to girls, pathological short stature is also seen in significant numbers in girls. Both girls and boys should be rigorously investigated and

Corresponding author:

Dr. Luna Bajracharya

Assistant Professor, Department of Paediatrics,

Tribhuvan University Teaching Hospital, Kathmandu, Nepal

Mobile no.9841313950

Email: luna.bajracharya@yahoo.com managed for short stature. ${ }^{2}$

According to Nepal Demographic and Health Survey (NDHS) 2017, the prevalence of stunting and underweight among children under age 5 years have markedly decreased from $57 \%$ to $36 \%$ from the year 1996 to 2016 . The same study showed mountain zone had the highest proportion of children who are stunted (47\%). Similarly, out of total 7 provinces, Province 6 had the highest proportion of stunted children (55\%) while Province 3 and Province 4 have the lowest proportion of stunted children $(29 \%)$ each. Also stunting was more common in children born to uneducated mothers and those from the lowest wealth quintile. ${ }^{6}$

A study done by Gaire et al found that among children aged 6-11 months, non vaccinated children, children of working women, children who live in mountainous areas, and children from the poorest households were more likely to be moderately stunted. Whereas children aged 36-47 months, Dalit and other ethnic groups, children from rural settings, and children from the poorest households were found more likely to be severely stunted. ${ }^{7}$ In a large Chinese screening study done 
in school children by Wang et al, it was found that short stature was more common in rural and economically backward conditions. ${ }^{8}$

How adverse socioeconomic conditions negatively affect child growth was also demonstrated in a large study conducted in United Kingdom by Voss et al. They have pointed out that no child, whatever the parental height, should be dismissed as normal without careful evaluation. They have suggested that poor growth in the early years may be an important pointer to an adverse but potentially remediable environment. ${ }^{9}$

It has also been suggested that early stunting is associated with greater deficits in long-term outcomes than would be expected from the persistent short stature alone. ${ }^{10}$

Short stature may be obvious when it is markedly noticeable but for early detection of subtle growth delays require use of growth measurements history to plot in a growth chart or height comparison with other family members. ${ }^{4}$

There are many growth charts like the World Health Organization (WHO) growth charts, Centre for Disease Control and Prevention (CDC) growth charts, syndrome, regional and ethnicity based growth charts. WHO growth charts and CDC growth charts both differ in the conceptual approach to describing growth and hence results for the same height may fall into different categories. ${ }^{11} \mathrm{~A}$ national consensus among all stake holders should be developed so as to use appropriate growth chart for the child under different circumstances.

One of the first and the essential steps in the evaluation of short stature is the accurate measurement and plotting of height in the growth charts.11Height velocity is the perhaps most important tool in the evaluation of linear growth over a period of time. The need for uniformity and accuracy in measurements of height and weight and subsequent proper documentation in growth charts is of utmost importance. ${ }^{4}$ Provision should be made so that any discrepancies in measurement are correctly and timely addressed.

A diagnostic evaluation is warranted if a child is "falling off" the height percentile or crossing two major percentile lines between age 2 years and the onset of puberty. ${ }^{12}$

Measurement of upper segment/ lower segment ratio, arm span, body mass index (BMI) and other markers of obesity with sexual maturation status etc should also be carried out simultaneously in a child with short stature where applicable. ${ }^{11,13}$

\section{Causes of short stature and approach}

It is estimated that approximately $5 \%$ of children who have undergone evaluation for short stature have an identifiable pathological cause. ${ }^{14}$ However, in a study done by Phirke et al, where 49 children underwent evaluation for short stature, almost three fourth of the children were found to have pathological cause for short stature. Among them, $24 \%$ had systemic cause where as malnutrition and endocrine cause was found in $12 \%$ each. ${ }^{15}$ The infancy phase of growth which has been assumed to begin at mid gestation and taper off around 2 to 3 years is regarded as predominantly nutrition dependent.11 Malnutrition at this phase of growth can lead to stunted growth.

Both constitutional growth delay and familial short stature are normal variants in growth of a child. ${ }^{4}$ A study done by Bhadada showed that the constitutional growth delay was the commonest cause for short stature in boys where as familial short stature was the commonest cause in girls. On the other hand, endocrine cause was the most common pathological cause. ${ }^{16}$ In pathological short stature, finding the cause and timely interventions may lead to attainment of expected height and avoidance of future medical and psychosocial complications.

Underweight with short stature points towards a systemic illness or malnutrition. ${ }^{3}$ Obesity or preserved weight with short stature is often seen 
in endocrine conditions such as hypothyroidism, growth hormone deficiency and excess cortisol conditions or in some genetic conditions. ${ }^{3,4,5}$ After two years of age, growth hormone plays an important role in height development whereas in the pubertal and adolescent years, sex hormones dominate. $^{3} \quad$ Bone age is commonly measured in evaluation of short stature. Bone age that is more than two standard deviations below from the mean for age is likely due to a pathologic condition. Progressive delay of bone age observed from serial radiographs yearly may favor an endocrine cause for growth delay. ${ }^{3}$

Growth hormone $(\mathrm{GH})$ deficiency has an incidence

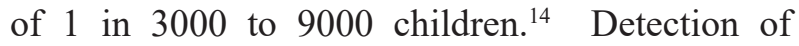
growth hormone level is done in National Public Health Laboratory (NPHL) in Kathmandu itself. Growth hormone stimulations test can be done at specialized centers. Growth hormone deficiency can be both congenital and/ or acquired. Detecting GH deficiency may also lead to detection of other associated hormonal dysfunctions, mainly related to the pituitary gland. This may require more additional laboratory tests and expensive imaging modalities such as Magnetic resonance imaging (MRI) of head etc. Also needed is a consensus among involved stake holders to devise a protocol for testing for growth hormone deficiency. Although growth hormone management is vailable in the country, the cost of treatment is very high. Many cannot afford to initiate or continue growth hormone treatment due to financial constraints. Government funding and a subsidized rate for treatment will make management available for those who need such therapy but cannot afford. Replacement of other hormones apart from growth hormone should be considered in cases of panhypopituitarism.

Infants born small for gestational age (SGA) are at increased risk of persistent short stature. ${ }^{17}$ SGA newborns of short mothers are at particularly high risk of stunting. ${ }^{18}$ According to Child Health Epidemiology Reference Group Small-forGestational-Age/Preterm Birth Working Group, there are approximately 6.5 million small for gestational age (SGA) and/or preterm births annually who may be associated with short maternal stature in lower middle income countries. To reduce this burden, they have pointed out the need for primary prevention of SGA, improvement in postnatal growth through early childhood, and possibly further intervention in late childhood and adolescence. ${ }^{19}$

Short stature in the current generation may also have long lasting consequences even to the next generation as shown by a study done by Tripathi and team. ${ }^{20}$ It showed that the incidence of instrumental delivery, risk of caesarean delivery, major genital tract injury and incidence of newborn with low birth weight was higher in short stature mothers. The vicious cycle of short mother having short children should be broken.

With wide spread availability of thyroid function testing and $\mathrm{x}$-rays for bone age estimation, such basic investigations in evaluation can be done and this should be used to its full potential. Presentation of juvenile hypothyroidism can be varied. In a study done by Karki ST et al, more than two third of the children with hypothyroidism had stunted growth. ${ }^{21}$ Prompt diagnosis and timely proper treatments can improve the thyroid related skeletal defects. ${ }^{22}$ The attainment of normal adult height in such cases depend upon the duration of untreated hypothyroidism, adequacy of treatment and the confounding effects of the onset of puberty. ${ }^{4}$ In a study done in Kathmandu, improvement in anthropometry was observed in children with hypothyroidism after being treated with thyroxine. ${ }^{23}$ Further, concern for new born screening for congenitalhypothyroidism has begunin the country ${ }^{24}$

Similarly, glucocorticoid excess which can lead to stunted growth can be endogenous or exogenous in origin. Reaching a normal adult height in such cortisol excess conditions will depend upon amount, duration of steroids excess and its complex interaction with sex steriods.

Celiac disease is also seen as a cause for short 
stature. ${ }^{13}$ A study done in Bikaner, India also found that among short stature children, celiac disease was not so uncommon. This led the authors to conclude that all short stature children should be screened for celiac disease. ${ }^{25}$ Testing of this condition should also be considered in our set up.

Various chromosomal abnormalities such Turner's syndrome, Noonan syndrome, Down's syndrome etc. can also present as short stature. ${ }^{13}$ In girls, Turner's syndrome as a cause of short stature is not commonly diagnosed in Nepal. ${ }^{26}$ Karyotype testing is performed within the country at the Genetics Lab of government tertiary health care institution which is National Academy of Medical Sciences (NAMS), Bir Hospital in Kathmandu. Renal function test, liver function tests, many hormone tests and other relevant tests are available in most of the other Government tertiary health care as Tribhuvan University Teaching Hospital (TUTH), National Public Health Laboratory (NPHL ) and private health institutions and laboratories.

Attention should also be focused on other medical aspects such as possible cardiac and renal problems in some syndromes with short stature. Other causes of short stature such as suspected skeletal dysplasia, liver disease etc should be evaluated and managed accordingly.

\section{Developing Network for Short Stature Management}

To be aware of the problem of short stature is the beginning of the solution. So in approach to short stature, awareness of the situation can be created early.

AWARNESS PROGRAMS

SCREENING PROGRAMS DIAGNOSTICS AND MANAGEMENT

\begin{tabular}{|c|c|c|}
\hline $\begin{array}{l}\text { Written information } \\
\text { on short stature } \\
\text { distributed at the } \\
\text { time of Delivery }\end{array}$ & $\begin{array}{l}\text { Screening done } \\
\text { at various } \\
\text { schools }\end{array}$ & $\begin{array}{l}\text { Local and Regional } \\
\text { Health Institutions for } \\
\text { further evaluation } \\
\text { and data collection }\end{array}$ \\
\hline $\begin{array}{l}\text { Information given } \\
\text { through radio, } \\
\text { television and other } \\
\text { mass } \\
\text { communication } \\
\text { mediums }\end{array}$ & $\begin{array}{l}\text { Screening done } \\
\text { at child health } \\
\text { care centers and } \\
\text { local ward health } \\
\text { clinics }\end{array}$ & $\begin{array}{l}\text { Central and tertiary } \\
\text { care hospital for } \\
\text { logistical support, } \\
\text { extended evaluation } \\
\text { and management } \\
\text { Data analysis }\end{array}$ \\
\hline $\begin{array}{l}\text { Information } \\
\text { provided in the } \\
\text { school health } \\
\text { related curriculum }\end{array}$ & $\begin{array}{l}\text { Screening done } \\
\text { during } \\
\text { vaccinations and } \\
\text { child health care } \\
\text { programs }\end{array}$ & $\begin{array}{l}\text { Possible } \\
\text { development of } \\
\text { country's own growth } \\
\text { chart and algorithm } \\
\text { based on data }\end{array}$ \\
\hline
\end{tabular}

Figure 1 : Suggested Integrated approach for short stature management 
A retrospective study done in China by $\mathrm{Wu} \mathrm{S}$ et al showed there is an increasing tendency to focus on children's height by parents from 2007 to $2015 .{ }^{27}$

A small simplified booklet with compilation of childhood developmental milestones, growth and puberty, breast feeding, nutritional advices, danger symptoms of common disease, vaccination schedules etc can be made. Maternity hospitals and Health centers with birthing facilities can begin a campaign of awareness by free distributing of these written information booklet to every parent after birth of every new born. This will also educate the whole family looking after the baby and the mother. In the age of social media and internet, various platforms can be used for broadcasting authoritative health advices from health professionals. These audio visual programs can be used in mass education as well. Measurement of height and weight done at vaccination programs and local ward clinics are also useful in analyzing rate of growth when documented in growth chart. Socioeconomic conditions, family dynamics, feeding and health issues can also be reviewed at the same time as these clinics may be quite familiar with the parents and their household conditions. Parental height provides clue to familial short stature. Documentations of parental heights can be done both in ward clinics as well as school for mid parental height estimations. Local Government bodies such as ward offices can also co-ordinate, bring experts at regular intervals to assess and collect data.

With the full implementation of Nepal Government plans to have provision of a nursing staff in each school, the process of recording growth, screening for defects and prompt referrals for needy cases will be much easier. The program of having one nurse for one school has already started in some parts of the country. ${ }^{28} \mathrm{~A}$ report prepared by Nepal Health Research Council NHRC) and Deutsche Gesellschaft fur Internationale Zusammenarbeit (GiZ) GmbH has shown that school based health workers in Nepal will help in many aspects including raising awareness and support provision..$^{29}$ Having a school based short stature awareness initiative may also bring forth hidden worries and psychosocial pressure among short stature students who would normally may not have access to seek health services. ${ }^{30}$ Height issues are often seen in families with financial difficulties in Nepal. ${ }^{6}$ A school based program will help in detecting such issues health much earlier. Thus detected short stature can then be referred to local, regional and even tertiary care for further evaluation and management. This should be done without undue delay and based on necessity.

Regular training for health staff on simple questionnaire interview tools to detect the cause of short stature, provision of use of a weighing machine, a stadiometer or a measuring tape for the periodic height and weight measurements of students can be done routinely. A network can be created with nurses and allied health personnel for information and data sharing. It can be linked with local and central health institutions for optimum planning (Figure 1). Care for growth related issues can be integrated into broad based child health care programs that may involve vaccinations, nutrition programs etc.

Besides, the data thus collected can also be used to develop our very own growth chart but this could be a daunting task in a country with multiethnicity with wide geographical variations. Data generated from various screening programs organized at local, community and regional levels can be analyzed. This can generate information such as efficacy of iodination programs hence need for further reinforcement of nutritional programs. These initiatives will encourage and restore better maternal and child care programs as well as preventive health measures for short stature.

A national government board for treatment of short stature can be set up to determine the benefits of major long therapeutic interventions such as growth hormone replacement therapy in view of huge costs. The potential risk of hormonal therapy especially in cases of marginal short stature and those who are happy to remain as "normal" short stature and those 
if left unattended with pathological short stature cases need careful assessment. Inappropriate investigation and therapy should be minimized with adequate psychosocial counseling. Assurance and timely treatment should be started where indicated so an integrated approach to management of childhood short stature is essential.

\section{References}

1 Allen DB, Cuttler L. Short Stature in Childhood - Challenges and Choices. N Engl J Med 2013; 368:1220-8

2 Grimberg A, Lifspitz F. Worrisome Growth .In Fima Liftstitz Editor. Paediatric Endocrinology. 5th edition. NewYork (USA) .Informa health care .2007;1(2): 1-30

3 Barstow C, Rerucha C. Evaluation of Short and Tall Stature in Children. Am Fam Physician. 2015;92(1):43-50

4 Rose SR, Vogiatzi MG, Copeland KC. A General Pediatric Approach to Evaluating a Short Child. Pediatrics in Review. 2005;26(11):410-20

5 Chianese J. Short Stature. Pediatrics in Review. 2005;26(1):36-37

6 Nutrition of Children and Adults. Nepal Demographic and Health Survey 2017: Key Indicators. Ministry of Health, Nepal; New ERA; and ICF. 2017. 223-258

7 Gaire S, Darge DT, Pandey S, Guha-Sapir D .Impact of disasters on child stunting in Nepal. Risk Manag Healthc Policy .2016;9:113-127

8 Wang Q, Liu D, Yang L, Liu y, Chen X. The epidemic characteristics of short stature in school students. Italian Journal of Pediatrics 2015; 41(99)

9 Voss LD, Mulligan J, Betts PR. Short stature at school entry--an index of social deprivation? Child Care Health Dev.1998; 24(2):145-56.

10 Wells JCK, Devakumar D, Manandhar DS, Saville N, Chaube SS, Costello A, Osrin D. Association of stunting at 2 years with body composition and blood pressure at 8 years of age: longitudinal cohort analysis from lowland Nepal. Eur J Clin Nutr. 2019; 73(2):302-310
11 Pinas-Hamiel O, Czernichow P, Zeitler P, Allen DB . Normal Growth and Growth Disorders. In Kappy MS, Allen DB, Geffner ME Editors . Paediatric Practice Endocrinology. 2ND Edition. New Delhi (India) . McGraw Hill Education (India) Private Limited. 2015; 27-93

12 Braun LR, Rose Marino R, Disorders of Growth and Stature Pediatrics in Review. July 2017 ; 38 (7) ;293-303)

13 Bhatia V, Dabadghao P. Normal Growth. In : Desai MP, Menon PSN, Bhatia P. Editors . Paediatric Endocrine Disorders. 2ndEdition.. Hyderabad (India). University Press. 2009; 6172

14 Lindsay R, Feldkamp M, Harris D, Robertson J, Rallison M. Utah Growth Study: growth standards and the prevalence of growth hormone defi $\neg$ ciency. J Pediatr. 1994;125 (1):29-35.

15 Phirke DS, Phirke SO, Khot S. An aetiological evaluation of short stature. IJRMS.2017; 5 : (9): 3887-90

16 Bhadada SK, Agrawal NK, Singh SK, Agrawal JK. Etiological profile of short stature. The Indian Journal of Pediatrics. July $2003 ; 70$ (7): 545-47

17 Clayton PE, Cianfarani S, Czernichow P, Johannsson G, Rapaport R, Rogol A. Management of the child born small for gestational age through to adulthood: a consensus statement of the International Societies of Pediatric Endocrinology and the Growth Hormone Research Society. J Clin Endocrinol Metab. 2007 Mar; 92(3):804-10

18 Xie C, Epstein LH, Eiden RD et al. Stunting at 5 Years Among SGA Newborns. Pediatrics. 2016;137(2):e20152636

19 Kozuki N, Katz J, Lee AC, Vogel JP, Silveira MF, Sania A, Stevens GA, Cousens S, Caulfield LE. Short Maternal Stature Increases Risk of Small-for-Gestational-Age and Preterm Births in Low and Middle-Income Countries: Individual Participant Data Meta-Analysis and Population Attributable Fraction. Child 
Health Epidemiology Reference Group Smallfor-Gestational-Age/Preterm Birth Working Group. J Nutr 2015; 145(11):2542-50

20 Tripathi M, Chaudhary P. Fetomaternal outcome in relation to maternal height among primigravidas. J-GMC-N. 2009;2(4): 18-23

21 Karki ST, Rai G, Karki B, Gurung R. Clinico-aetiological Profile of Congenital Hypothyroidism. Journal of Nepal Paediatric Society. 2016; 36(2) : 126-30.

22 Gutch M , Kumar S, Razi SM, Gupta A, Kumar S, Gupta KK, Singh MM. Prevalence of short stature in juvenile hypothyroidism and the impact of treatment on various skeletal manifestation and growth velocity in a teritary care center. CHRISMED J Health Res 2015;2:251-6

23 Bajracharya BL, Baral MR , Thapa Chhetri P . A study of therapeutic effect of the growth of children with hypothyroidism. Kathmandu University Medical Journal. 2006 ; 4 (3) :15 :329-33

24 Bajracharya L. Neonatal thyroid screening for congential hypothyroidism. Journal of Diabetes and Endocrinology Association of Nepal. 2019; 3(1): 32-3.

25 Mali L., Meena S., Khatri P., Kumar TV, Kumar P. Clinical and Nutritional Assessment of Short Statured Indian Children with Celiac
Disease. Journal of Nepal Paediatric Society. 2013; 33(2) : 91-4.

26 Basnet S, Eleena A, Sharma A. Turner Syndrome, Uncommonly Diagnosed Cause of Short Stature: Case Report and Review of Literature. Journal of Nepal Paediatric Society .2013; 33(1), 74-6.

$27 \mathrm{Wu}$ S, Liu QQ, Gu W, Ni SN, Shi X, Zhu ZY. A Retrospective Analysis of Patients with Short Stature in the South of China between 2007 and 2015 .BioMed Research International .2018. Article ID 5732694

$28 \mathrm{ht} \mathrm{tps}: / / \mathrm{kathm}$ and upost.com/ miscellaneous/2018/12/19/province-3launches-one-school-one-nurse-project. Accessed on December 62019.

29 Dhimal M, Chalise B, Jahan I, Thapa S, Neupane T, Timsina A, Jha BK, Bista B, Pandey AR, Jha AK . School Based Health Workers in Nepal: Supporting Evidence Based Decission Making. Kathmandu, Nepal Health Research Council and GiZ; 2018

30 Voss LD. Is short stature a problem? The psychological view. European Journal of Endocrinology ,2006; 155: S39-S45 